\title{
BIOtinga: TRILHA DE GAMIFICAÇÃO SOBRE A CAATINGA
}

\author{
Paloma Clementino da Cruz Lubarino ${ }^{1}$ \\ Josiel Bezerra dos Santos ${ }^{2}$ \\ Elâine Maria dos Santos Ribeiro ${ }^{3}$ \\ Regina Lúcia Félix de Aguiar Lima ${ }^{4}$
}

Resumo: A gamificação propõe utilizar elementos de jogos em ambiente de não jogo. O desenvolvimento da trilha de gamificação denominada BIOtinga tem por objetivo promover o conhecimento sobre a biodiversidade da Caatinga e da região semiárida brasileira, de forma interativa. A trilha de gamificação elaborada é sobre uma criança sertaneja vivendo uma aventura em uma fazenda na Caatinga, onde contará com a ajuda de animais da região para combater um vilão que destrói o ambiente. A proposta pedagógica contribui para o uso de tecnologias no ambiente escolar, para favorecer a compreensão dos conteúdos sobre a biodiversidade da Caatinga, e para promover no processo educativo maior interatividade e dinâmica.

Palavras-chave: Metodologia Ativa; Ensino Offline; Ensino Fundamental; Semiárido; Jogos.

Abstract: Gamification proposes to use game elements in a non-game environment. The development of the gamification trail called BIOtinga aims to promote knowledge about the biodiversity of the Caatinga and the Brazilian semi-arid region, in an interactive way. The gamification trail elaborated is about a country boy living an adventure on a farm in the Caatinga, where he will count on the help of animals from the region to fight a villain who destroys the environment. The pedagogical proposal contributes to the use of technologies in the school environment, to favor the understanding of the contents about Caatinga biodiversity, and to promote greater interactivity and dynamics in the educational process.

Keywords: Active Methodology; Offline Teaching; Elementary School; Semiarid; Games.

\footnotetext{
${ }^{1}$ Universidade de Pernambuco, E-mail: paloma.lubarino@upe.br. http://lattes.cnpq.br/1584332712039684

2 Universidade de Pernambuco, E-mail: josiel.bezerra@upe.br. http://lattes.cnpq.br/0875558635316554

3 Universidade de Pernambuco, E-mail: elaine.ribeiro@upe.br. http://lattes.cnpq.br/3304685448889789

4 Universidade de Pernambuco, E-mail: regina.aguiar@upe.br. http://lattes.cnpq.br/8549101690272163
} 


\section{Introdução}

A Caatinga, apesar de ser um dos ecossistemas mais ameaçados do Brasil, também é um dos menos estudados e conhecidos, até mesmo pela população que vive nesta região. Por apresentar clima tropical semiárido, consequentemente, enfrenta longos períodos de seca e alta estiagem (ARNAN, 2018). Por esse motivo, a fauna e a flora, desta região, desenvolveram resiliência para sobrevivência com a pouca disponibilidade de água. Além disso, é importante dizer que as ações antrópicas também fazem parte da contribuição para 0 aumento da degradação da Caatinga e que o gerenciamento dos seus recursos naturais é urgente para a restauração e conservação ambiental (ANTONGIOVANNI, 2020). Portanto, há uma grande necessidade de se conhecer o potencial da Caatinga, em todos segmentos da sociedade, dando ênfase à capacitação e ao aprofundamento dos conhecimentos relacionados à sustentabilidade para garantir não somente a geração de renda para a população, mas também os serviços ecossistêmicos disponibilizados como resultados da conservação (PEREIRA, 2020).

O uso de estratégias baseadas em metodologias ativas de aprendizagem podem ajudar nesse processo de valorização da Caatinga. Essas metodologias colocam o estudante como protagonista da aprendizagem, sendo estimulado pelos professores para o desenvolvimento de habilidades e competências para a internalização dos conteúdos de maneira ativa e significativa (FERREIRA, 2019). Sendo assim, não custa dizer que os recursos didáticos baseados em metodologias ativas, tais como aprendizagem baseada em projetos, em problemas, em jogos, estudo de caso e trilha de gamificação têm se mostrado eficientes na transposição didática, vencendo as formas fixas da educação tradicional e a atuação do professor como o centro das atenções (BRISOLLA, 2020).

A gamificação aplicada à aprendizagem é uma metodologia ativa, que consiste na utilização do conceito e da estrutura dos games para despertar nos alunos engajamento em uma ação, motivação para resolução de problemas e obtenção de um resultado que inclui aprendizagem, isso tudo em um ambiente com tempo, espaço, interações diversas e regras específicas (ALVES, 2018). De forma geral, a gamificação busca atrelar as necessidades que os alunos possuem em relação à aprendizagem dos conteúdos das aulas ministradas pelos professores, e a resolução do déficit de aprendizagem desses alunos ao longo da história escolar deles. Com isso, a gamificação representa muito mais do que a satisfação de entreter-se e vai além das necessidades básicas da decodificação das palavras. Veem-se, nesse ponto, estratégias de gamificação que visam tornar o processo ensino-aprendizagem mais prazeroso e com mais autonomia por parte dos alunos, com o intuito de fazer os alunos se identificarem com as atividades desenvolvidas nos ambientes de trocas de conhecimentos (KINGSLEY, 2018).

Diante do contexto apresentado, esta proposta apresenta a aplicação 
sobre a biodiversidade Caatinga e a região do semiárido brasileiro, com vistas a contribuir para sua valorização e conservação.

\section{A importância da utilização da gamificação no ambiente escolar}

A gamificação visa proporcionar conhecimentos de maneira prazerosa com a utilização de jogos, de forma consciente, com a resolução de desafios mediante ações que garantam sentido diante das realidades vividas pelos participantes do processo, de atividades relevantes que deem motivação, estímulo e, consequentemente, a continuidade as atividades vivenciadas (CHOU, 2016). A gamificação inclui o jogo em um ambiente de não jogo para alcance de um propósito definido pelas partes envolvidas no processo de aprendizagem dos indivíduos (ALVES, 2014). Dessa forma, embora a gamificação seja considerada um jogo, é importante mencionar que ela difere, de um simples jogo, por apresentar finalidades ligadas além do entretenimento das pessoas, viabilizando formas diferentes de aprender determinados assuntos e sobre tudo, potencializando os recursos dos jogos tradicionais (MENEZES, 2017).

A gamificação se constitui uma ferramenta estratégica voltada para o processo de ensino e aprendizagem que atua no despertamento, dos alunos, em querer aprender fortalecendo, assim, os fatores ligados ao emocional, cognitivo e social das pessoas (ALVES, 2018; XI, 2020). Por isso, a gamificação contribui para o aprendizado mais efetivo, tanto dos professores como dos discentes, e dinâmico tornando o ambiente mais agradável (RIBEIRO, 2020). A aplicação de estratégia de gamificação na Educação Ambiental produziu resultados desejados em termos de promoção da conscientização ambiental e da ampliação dos conhecimentos sobre os temas abordados (SANTOS et al. 2016). Além disso, contribui para atribuir valores sociais, culturais, históricos; a gamificação exerce função de satisfazer as necessidades dos discentes na conquista do saber (ALVES, 2018).

Diante do novo cenário mundial frente à pandemia da Covid-19 o ensino a distância se tornou uma necessidade real para minimizar as barreiras concernentes de acesso à educação em situações atípicas (JOYE et al. 2020). A inclusão digital, ou seja, o acesso à rede mundial de computadores com interação global da internet faz com que as distâncias sejam anuladas; porém, devido às grandes desigualdades sociais, no Brasil, nem todas as pessoas usufruem das tecnologias disponíveis nessa nova era. Desenvolver e adaptar aulas tradicionais no meio virtual tornou-se um grande desafio para as escolas, principalmente, para as que têm maior número de alunos com baixo poder aquisitivo (SAMPAIO, 2020). Nesse cenário, as escolas devem encarar os desafios tecnológicos e metodológicos e buscar aliar metodologias ativas e inclusão digital para atravessar essa situação e ainda inserir os alunos nesse mundo novo. 
A tendência mundial do ensino digital veio para ficar, e o celular é hoje um recurso acessível à grande parte da sociedade e aliado na educação dos alunos quando embasado em uma proposta pedagógica bem consolidada (SOUZA, 2015). O microlearning (do inglês, micro aprendizagem) é uma abordagem de ensino que transmite pequenas doses de conhecimentos em um curto espaço de tempo, utilizando recursos digitais tais como podcasts, vídeos, tutoriais, textos e jogos diversos (GIURGIU, 2017). Por meio do celular, utilizando o método microlearning, um conteúdo complexo é construído através de pequenas partes, em forma de sessões de aprendizagem. Aliado a esses fatores, os alunos que são da geração $Z$, por terem nascido na era digital, precisam de multiformatos no processo de ensino-aprendizagem, também chamados de nativos digitais têm sede por conhecimento e novidades (QUINTANILHA, 2017). Essa geração busca inovações e recursos tecnológicos para resolução de questionamentos ligados a assuntos contextualizados com a realidade local da comunidade. A gamificação é uma das estratégias de metodologias ativas que vai de encontro aos anseios dessa geração.

Os elementos usados na gamificação permeiam a dinâmica que tem o papel fundamental de dar motivo à ação de resposta à mecânica, onde compreende a dimensão de diversas formas de expressões inerentes à comunicabilidade, resultando em relações saudáveis e ecológicas dos atores participantes dos desafios propostos pela gamificação (MARTINS, 2016). Dentro de uma visão holística da gamificação, pode-se evidenciar o uso de elementos que também são utilizados em jogos comuns, como, por exemplo, meta, regras, feedback e a voluntariedade na participação dos jogadores, sendo capaz de chamar à atenção e motivar o envolvimento desses (BRAZIL, 2020). Em relação ao conhecimento dos elementos compartilhados na gamificação, verifica-se a criação de histórias, narradas, baseadas no seu público-alvo, sendo possível a personalização de um avatar com seus desafios, conquistas e missões.

Então, pensando na difusão de conhecimentos sobre a Caatinga e no protagonismo dos alunos no processo ensino-aprendizagem, observa-se que vários questionamentos são elaborados e precisam ser respondidos, por exemplo, como integrar a valoração da Caatinga no ambiente escolar digital offline? O objetivo pedagógico do BIOtinga é ensinar sobre as características gerais da Caatinga, considerando a utilização da Educação Ambiental como ferramenta primordial à garantia dos princípios seus básicos como, por exemplo, o enfoque humanista e democrático, pluralismo de ideias e a ética (CARSON, 1969; FREIRE; PACHECO, 2017).

A aprendizagem será direcionada para a prática, e o conteúdo, para os resultados. Assim, o aluno irá usar sua autonomia para seguir a trilha de aprendizagem e montar seu próprio avatar, pois, segundo Chou (2016), o motivo da criação de avatares é estimular o engajamento dos participantes. Para que haja o processo de ensino-aprendizagem, a trilha será composta de enigmas, que compreendem os desafios encontrados em cada fase do jogo 
exigindo, assim, o conhecimento prévio do aluno entrelaçado ao científico para poder passar à próxima fase (AVERY e MICHALEWICZ, 2010).

Pode-se dizer que a gamificação utilizada como recurso inclusivo na educação brasileira tem sido arma poderosa para envolver os jogadores com as atividades desenvolvidas. Neste contexto, para Chou (2016) fica claro que o processo de aproveitamento mediante uso de jogos impulsiona de formas diferentes as pessoas, como, por exemplo, estimulando a serem criativas. Entretanto, o mais preocupante é constatar que nem todos os atores envolvidos podem participar das interações tecnológicas devido à falta de acesso a dispositivos e internet.

\section{Metodologia}

A construção da trilha de gamificação BIOtinga foi feita utilizando de forma lúdica elementos de jogos no ambiente escolar (MARTINS et al. 2020). A trilha de gamificação busca motivar os alunos por meio de elementos como a competição, definição de objetivos e sistemas de recompensa. A BIOtinga foi elaborada, tendo por fundamentação as cinco etapas da gamificação (MARTINS et al. 2020), que são: objetivo pedagógico, atividade, narrativa, construção das trilhas e inserção dos três elementos de jogos de forma dinâmica dentro da atividade.

A primeira etapa é a definição do objetivo pedagógico da BIOtinga, que é caracterizar os aspectos históricos, físicos, climáticos, humanos, de biodiversidade e conservação da Caatinga. A segunda e terceira etapas são a atividade e a narrativa, respectivamente. $\mathrm{Na}$ atividade, o aluno terá que alcançar os objetivos da 'Quest'(investigação) e a narrativa irá conectar o 'início' até o 'fim de jogo', que traz como história a Caatinga, que será a vítima por estar em perigo constante (poluição dos rios, do solo, desmatamento e desertificação). O aluno será o herói e utilizará seu avatar para descobrir formas de combater os crimes ambientais causados pelo vilão da história (o homem destruidor de Caatinga - DC e seus capangas). Ao longo do percurso, a criança sertaneja irá conhecer os vários aspectos da Caatinga, sendo envolvida com o sentimento de pertencimento e, ao final, o vilão será regenerado pela criança, transformando-o em um homem sertanejo cheio de valores e princípios.

A quarta etapa é a construção das trilhas composta por dois caminhos. Essas trilhas ligam os pontos de 'início' e 'fim de jogo'. Uma trilha utilizará como recurso um vídeo e a outra um texto. A quinta etapa é inserção dos três elementos (herói, vilão e jornada) de forma dinâmica dentro da atividade e cada elemento é composto de mais três representações. O elemento do herói representa o aluno, o vilão representa quem atrapalha o processo e a jornada representa o objetivo da atividade.

$\mathrm{Na}$ trilha, será contada a história de uma criança sertaneja que adora passar as férias com os avós na roça, localizada numa região onde ocorre 
Caatinga. Sua curiosidade irá levá-la a conhecer histórias sobre a Caatinga, aprender sobre as características do solo, clima e seres vivos do semiárido, além de fazer novas amizades, que irão ajudá-la a preservar a biodiversidade e combater o vilão da história, o homem DC e seus capangas.

A trilha de gamificação BIOtinga faz parte da proposta "Aprendendo sobre o valor da biodiversidade da Caatinga e seus serviços ecossistêmicos no ensino escolar" apoiada pela Fundação de Amparo a Ciência e Tecnologia do Estado de Pernambuco (APQ - 0177-2.05/18).

\section{Resultados e discussão}

\section{Estrutura da trilha de gamificação BIOtinga}

O BIOtinga tem um ponto de início, o qual se segue por duas trilhas com diferentes elementos e o final do jogo (Figura 1). No layout do BIOtinga são usados símbolos que representam os vários componentes do jogo (Tabela 1). São eles: os pontos de início e de fim de jogo e os três conjuntos de elementos do jogo (de herói, de vilão e de jornada).

Os elementos de herói são: sol, cacto e tatu-bola. O elemento de herói sol, marca o início do jogo, e representa o número de oportunidades, que será oferecido ao aluno, sendo que ele pode errar quantas vezes forem necessárias, mas terá somente uma chance de entregar o resultado final correto com 'feedback'. O aluno terá possibilidade de descobrir se conseguiu ou não alcançar esse resultado.

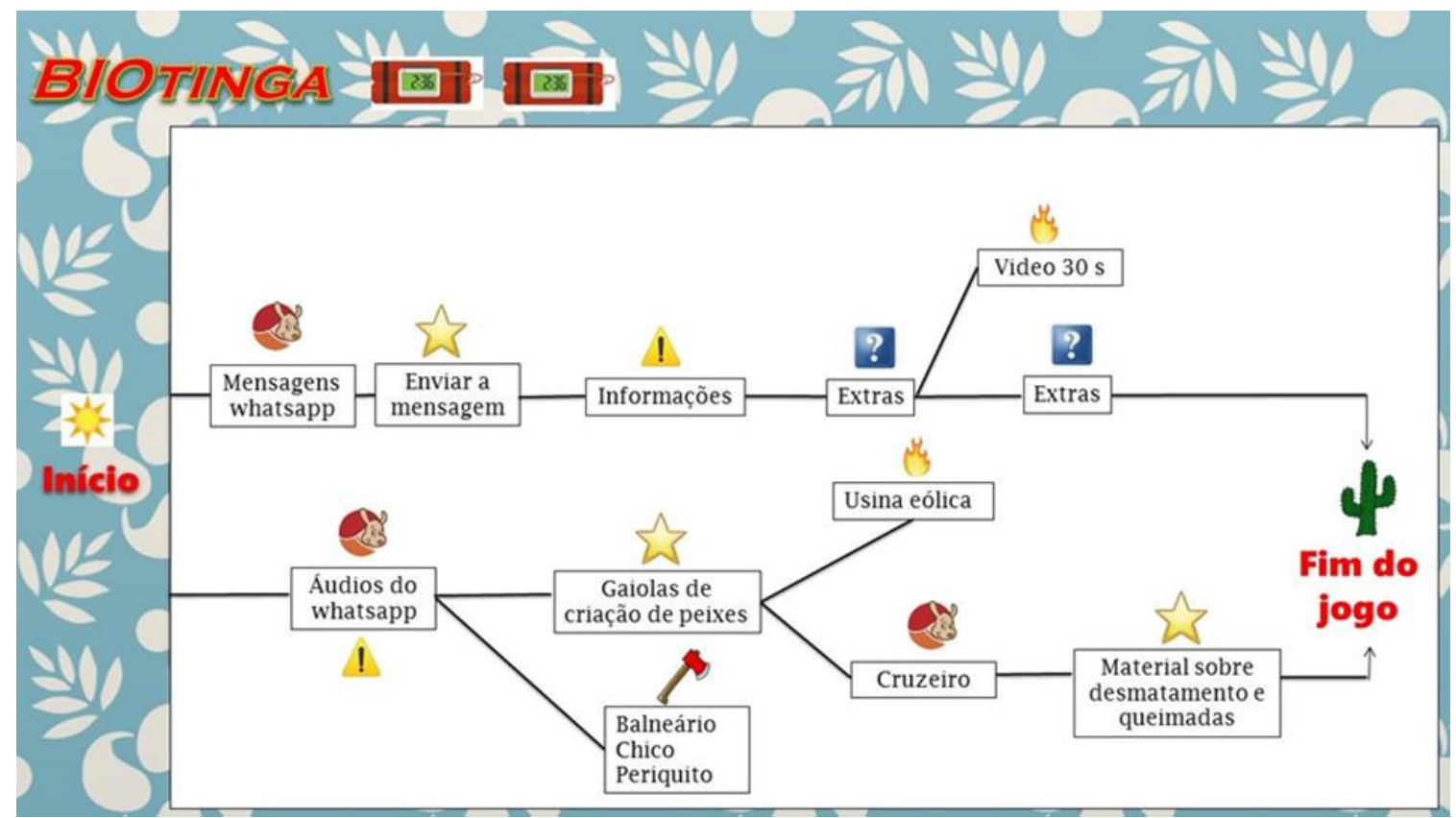

Figura 1: Layout para a programação da trilha de gamificação educativa BIOtinga Fonte: Autoria própria. 
O elemento de herói cacto representa o objetivo final; por exemplo, após descobrir todas as formas de combater os crimes ambientais, o aluno ajudará 0 vilão a entender que pode conviver pacificamente com o meio ambiente sem a necessidade de destruição. A chegada ao objetivo final, elemento de cacto, poderá acontecer por dois caminhos diferentes que contêm conjuntos de atividades diferentes, um deles iniciado por mensagens de texto e o outro por mensagens de áudio, ambas recebidas por WhatsApp. O elemento tatu-bola é uma ferramenta oferecida ao discente para cumprir os objetivos, por exemplo, um material que dá dicas, como um vídeo, um áudio ou um texto.

Tabela 1: Elementos de jogo da trilha BIOtinga e suas representações

\begin{tabular}{ccc}
\hline TIPO & NOME & SímBOLO \\
\hline Elemento de herói & Sol & Tatu-bola \\
\hline Cacto & Fogueira & \\
\hline Elemento de vilão & Machado & \\
\hline Elemento de jornada & Bomba-relógio & \\
\hline & Estrela & \\
\hline & Exclamação & \\
\hline
\end{tabular}

Fonte: Autoria própria.

Os elementos de vilão são: bomba relógio, machado e chama. O elemento de bomba-relógio representa o tempo que o aluno terá para desenvolver a atividade, por exemplo, uma bomba para cada aula. O elemento machado representa um fator de complicação para confundir o aluno, como, por exemplo, uma "pegadinha", informação falsa. O elemento chama representa um caminho falso na trilha. Esses dois últimos elementos levarão os alunos a realizarem uma pesquisa e usarem de raciocínio para entender que a 
dica significa que não é algo bom. Dessa forma, o aluno vai precisar voltar e buscar uma outra trilha diferente.

Os elementos de jornada são a estrela, interrogação e exclamação. A estrela representa a ferramenta que o aluno deverá ir atrás sozinho. Essa ferramenta dá autonomia ao aluno, por exemplo, de notar uma imagem, clicar e ver as informações. O elemento interrogação representa informação surpresa, que estará num determinado ponto da trilha. Por exemplo, no final da primeira aula, o aluno recebe mais uma informação como dica para facilitar o restante do percurso. Diante disso, vale salientar que outro elemento de jornada identificado pela exclamação representa informações auxiliares, que não contribuíram durante o percurso, mas farão sentido quando o aluno chegar ao resultado final do jogo.

\section{Narrativa da trilha de gamificação educativa BIOtinga}

A história se passa na Roça Cancela, localizada em Correnteza, distrito de Sobradinho, estado da Bahia. O termo roça é uma denominação popular para as propriedades rurais nas cidades de Petrolina, Juazeiro e adjacências, corresponde a sítio, fazenda.

Uma criança sertaneja, nas suas férias, vai à roça de seus avós, e lá ela vive momentos felizes e inusitados com seus amigos secretos (a abelhinha jandaíra, o veado catingueiro, o preá e o gato maracajá). Um dia, ao acordar, ela sente um mau cheiro e, ao indagar os avós sobre do que se tratava, percebeu que ninguém sabia o que estava acontecendo. Em seguida, seus amigos secretos vieram até a criança preocupados com o odor desagradável, com o adoecimento dos animais, e também com o manejo que os homens da roça vizinha estavam fazendo na Caatinga, onde os bichinhos moravam, a mandado de um homem, que eles intitularam de homem DC (Destruidor da Caatinga).

Para deixar o jogador muito curioso e mais motivado a percorrer a trilha inteira, faz-se necessário que o desafio seja proposto na forma de um mistério (CHOU, 2016) que precisa ser desvendado. Assim, as perguntas do mistério são: De onde vem o mau cheiro? Do que se trata? Por que o homem DC estava desmatando a Caatinga?

Esse é o ponto de partida do jogo, representado pelo elemento de herói sol, onde as possibilidades de escolhas pelos alunos são asseguradas e, consequentemente, a diminuição do medo de errar. No processo ensinoaprendizagem 0 saber fazer está inerente à tentativa de erros e acertos (WITTER, 2011). Isso é importante para o desenvolvimento dos alunos, porque será possível a aplicabilidade do protagonismo para construção do conhecimento. Dessa forma, Vicente e Araújo (2017) afirmam que a aprendizagem acontece ativamente e não passivamente. Partindo dessa visão, o aluno encontrará no caminho um aparelho celular desbloqueado e terá a oportunidade de escolher uma das duas opções. Se o aluno escolher investigar as mensagens do whatsapp fornecidas (representado pelo elemento de herói 
tatu-bola), ele acabará descobrindo o número que está enviando mensagens suspeitas (sobre produtos químicos e suas finalidades) e a quem pertence 0 celular (no caso, ao homem DC).

$\mathrm{Na}$ trilha, haverá a mensagem sobre defensivos agrícolas (agrotóxicos), evidenciando que são produtos químicos usados na agricultura que enfrentam os microrganismos e patógenos prejudiciais ao desenvolvimento da produção agrícola tal como o inseticida usado como exemplo na Figura 2.

INSECTO•

Registrado no Ministério da Agricultura, Pecuária e Abastecimento - MAPA sob o ne 02597

COMPOSICุĀO:

Silicon dioxide (TERRA DIATOMÁCEA). $867 \mathrm{~g} / \mathrm{kg}(86,7 \% \mathrm{~m} / \mathrm{m})$

Outros ingredientes $133 \mathrm{~g} / \mathrm{kg}(13,3 \% \mathrm{~m} / \mathrm{m})$

GRUPO 8D INSETICIDA

PESO LÍQUIDO: Vide Rótulo

CLASSE: Inseticida de contato

GRUPO QUIMICO: Inorgânico

TIPO DE FORMULAÇÃO: PÓ SeCO (DP)

TITULAR DO REGISTRO (*):

BEQUISA INDÚSTRIA QUIMICA DO BRASIL LTDA

Av. Antonio Bemardo, 3950 - Gleba 37 - Pq. Industrial Imigrantes - Conj. Residencial Humaitá

CEP: $11349-380$ - Săo Vicente/SP - Tel.: (13) 3565-1212 - CNPJ: 58.133.703/0001-78

Número de registro do estabelecimento/Estado (SAACDAVP) n ${ }^{\circ} 045$

(*) IMPORTADOR DO PRODUTO FORMULADO

FABRICANTE / FORMULADOR:

BEQUISA INDÚSTRIA QUIMICA DO BRASIL LTDA

Av. Antonio Bernardo, 3950 - Gleba 37 - Pq. Industrial Imigrantes - Conj. Residencial Humaitá CEP: $11349-380$ - Săo Vicente/SP - Tel.: (13) 3565-1212 - CNPJ: 58.133.703/0001-78

Número de registro do estabelecimento/Estado (SAACDAVSP) n 045

NATURAL INSECTO PRODUCTS, INC

630 N. Eckhoff Street - Orange, CA 92668 - EUA

MANIPULADOR:

BEQUISA INDÜSTRIA QUIMICA DO BRASIL LTDA

Av. António Bernardo, 3950 - Gleba 37 - Pq. Industrial Imigrantes - Conj. Residencial Humaitá CEP: 11349-380 - Sāo Vicente/SP - Tel: (13) 3565-1212 - CNPJ: 58.133.703/0001-78

Número de registro do estabelecimento/Estado (SAACDASP) $n^{\circ} 045$

\begin{tabular}{|l|l|}
\hline No do lote ou da partida: & \\
\hline Data de fabricaça: & VIDE EMBALAGEM \\
\hline Data de vencimento: & \\
\hline
\end{tabular}

ANTES DE USAR O PRODUTO LEIA O RÓTULO, A BULA E A RECEITA AGRONOOMICA E CONSERVE-OS EM SEU PODER. É OBRIGATORIO O USO DE EQUIPAMENTOS DE PROTEÇĀO INDIVIDUAL PROTEJA-SE

É OBRIGATÓRIA A DEVOLUÇĀO DA EMBALAGEM VAZIA.

Indústria Brasileira

Figura 2: Descrição de um inseticida, características e efeitos (trecho de uma bula) Fonte: Agência de Defesa Agropecuária do Paraná 2020.

$<$ www.adapar.pr.gov.br/arquivos/File/defis/DFl/Bulas/Inseticidas/insecto7201.pdf>

Contudo, o uso excessivo de defensivos agrícolas produz contaminação ambiental e resulta em problemas ambientais, intoxicação dos seres vivos, contaminação no solo e na água e problemas de saúde pública, doenças em humanos (LIMA-BOHNER et al. 2013). 
Sendo assim, o aluno deve chegar à conclusão de que há necessidade da elaboração de atividades de Educação Ambiental com o propósito de uso correto dos defensivos agrícolas e descarte adequado das embalagens para a conservação, preservação e sustentabilidade da Caatinga. Se o aluno enviar a mensagem para um número de celular fornecido, com uso do elemento de jornada estrela, ele receberá uma mensagem automática enviada por uma loja de produtos químicos para a agricultura, dessa forma ele descobre a origem do produto. Ao seguir na trilha, o aluno receberá informações sobre os riscos de uso indiscriminado de produtos químicos e seus efeitos no solo e na água, representado pelo elemento de jornada exclamação. Não custa dizer que são fundamentais as boas práticas de uso e manuseio de agrotóxicos na produção de alimentos para a agricultura familiar e suas interações ecológicas ligadas à saúde da comunidade em geral (BUSATO et al. 2019). A criança da Caatinga e seus amigos animais encontrarão um frasco de produto químico vazio, jogado na estrada. Nesse ponto, será entregue uma informação extra (elemento de jornada - interrogação), descrevendo a importância da biodiversidade e a preservação da Caatinga (Tabela 2).

Tabela 2: Frases com informações para gamificação educativa BIOtinga

\begin{tabular}{ll}
\hline Frase I & $\begin{array}{l}\text { Os ecossistemas da Caatinga, que sofrem com a destruição constante por ações } \\
\text { humanas, a adoção de práticas agrícolas prejudiciais aos solos diminuem sua } \\
\text { fertilidade solos, tornando-os pobres e, consequentemente, improdutivos, } \\
\text { trazendo, assim, a escassez de água de qualidade e a falta de alimentos para os } \\
\text { sertanejos. }\end{array}$ \\
\hline Frase II & $\begin{array}{l}\text { Os produtos químicos utilizados na agricultura para o manejo de pragas } \\
\text { fertilização podem atingir diretamente todas as formas de vida encontradas no solo } \\
\text { do sertão nordestino, resultando numa problemática para o meio ambiente, como, } \\
\text { por exemplo, a desertificação. }\end{array}$ \\
\hline Frase III & $\begin{array}{l}\text { Procedimentos de leitura dos rótulos de produtos químicos podem diminuir os } \\
\text { perigos de contaminação dos solos e lençóis freáticos, dos sistemas ecológicos, } \\
\text { através da importância das informações inseridas nas bulas dos agrotóxicos. }\end{array}$ \\
\hline
\end{tabular}

Fonte: Autoria própria.

Ao relacionar as informações, o aluno irá descobrir que o motivo dos animais terem adoecido e do mau cheiro que eles estavam sentindo está relacionado com o produto químico usado pelo homem DC (Figura 3) e seus capangas na plantação da roça dele. Mas o aluno ainda tem um desafio: precisa impedir que o homem DC continue aplicando a calda química que seus capangas haviam preparado. Para isso, o aluno precisa seguir na trilha. Se ele escolher o caminho com um vídeo de 30 segundos, representado pelo elemento de vilão chama, ele terá que ser perspicaz para entender que deve voltar para a trilha e buscar outra alternativa. 
Ao retornar para a trilha, o aluno receberá informações extras, (elemento de jornada - interrogação), que é um endereço eletrônico onde ele poderá acessar informações para desvendar enigmas da trilha (https://josielbezerra.blogspot.com/search?q=Caatinga), com indicações de alternativas agroecológicas para uso no combater às pragas e doenças. Com essas informações ele ajudará o homem DC a adotar sistemas de produção agroecológicos, gerando renda em convívio harmônico com a biodiversidade da Caatinga. Nessa etapa, o aluno alcançará o objetivo final, representado pelo elemento de herói cacto.

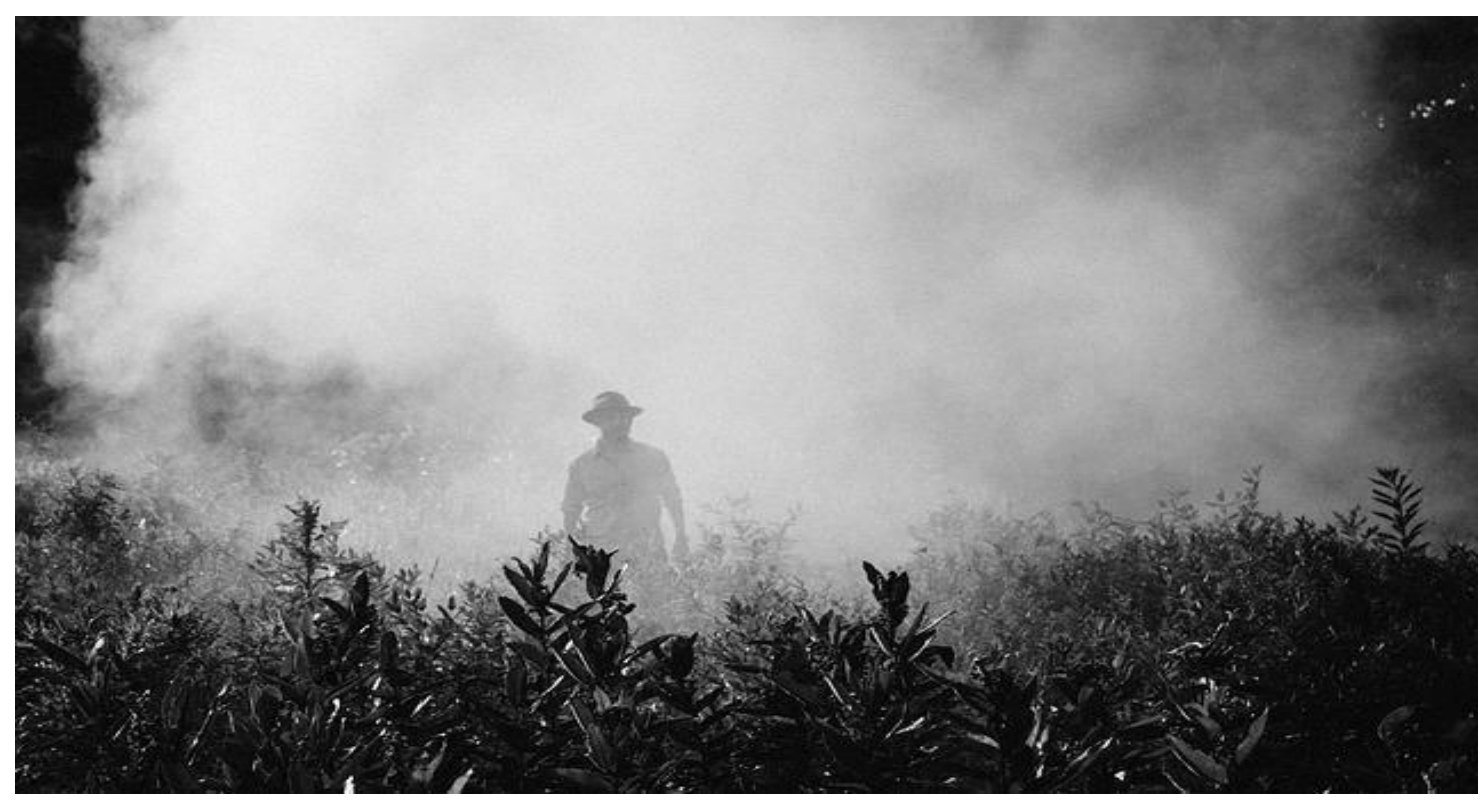

Figura 3. Imagem ilustrativa do homem destruidor de Caatinga (DC).

Fonte: https://pixabay.com/photos/fog-steam-person-farmer-spraying-918976/

Se o aluno escolher começar a investigação pelos áudios do whatsapp, (elemento de herói tatu-bola), ele acabará escutando sons de água e risadas no fundo do áudio,que indicarão pistas para duas direções, uma certa e outra errada, e também receberá uma dica auxiliar (elemento de jornada exclamação) indicando que as mensagens foram recebidas, mas não foram lidas. Na pista errada, representado pelo elemento de vilão machado, o aluno irá para o Balneário Chico Periquito e terá que voltar para a trilha. Na pista certa, representado pelo elemento de jornada estrela, o aluno irá para as gaiolas de criação de peixes no lago de Sobradinho.

No balneário, o aluno encontrará um grupo de estudantes do Programa de Pós-Graduação em Ciência e Tecnologia Ambiental - PPGCTA, que estará passando informações para a comunidade sobre economia sustentável (exemplo: gaiolas de criação de peixes, energia hidrelétrica, placas fotovoltaicas, história da inundação de cidades para formar o lago de Sobradinho, apicultura e integração Lavoura-Pecuária-Floresta - ILPF). A 
segunda dica, representada pelo elemento de vilão Chama, levará o aluno até a usina eólica. Aqui, o aluno precisa ser perspicaz para entender que precisa voltar à trilha. A próxima dica levará o aluno até o Cruzeiro, representado pelo elemento de herói tatu-bola; de lá de cima, ele verá o homem DC ordenando seus capangas a roçarem a área de preservação da Caatinga para marcar o território. Aqui, o aluno receberá informações sobre desmatamento e queimadas na Caatinga, suas finalidades e consequências, representado pelo elemento de jornada Estrela.

O aluno deve descobrir que o homem DC pretende desmatar e queimar a área marcada e terá que voltar para a trilha a tempo de impedi-lo. A informação dada no início da segunda trilha, representada pelo elemento de jornada exclamação, agora faz sentido; Como o homem DC perdeu o celular, ele não escutou os áudios. A criança irá mostrá-lo tudo que aprendeu durante a jornada e com os alunos do PPGCTA. Assim, em lugar de desmatar para vender a madeira e de queimar a Caatinga para criar gado, o homem DC será convencido a adotar práticas ecológicas na sua relação com a fauna e a flora da Caatinga, especialmente nas atividades de agricultura, pecuária e de obtenção de energia. Ele irá participar da Associação dos Criadores de Peixes de Sobradinho, instalará placas solares para aproveitar a luz do sol para gerar energia e adotará o sistema de ILPF. Nessa etapa, o aluno alcançará o objetivo final, representado pelo elemento de herói cacto.

\section{Conclusões}

A BIOtinga é uma aplicação da gamificação para a educação básica, sendo uma estratégia educacional, que pode ter grande importância para o aprendizado de todos os atores envolvidos no processo de ensino e aprendizagem, porque viabiliza a inclusão social, tecnológica e proporciona a interação dos indivíduos com o meio ambiente e a busca de conhecimentos sobre a Caatinga.

Dessa forma, a criação da gamificação atrelada à Educação Ambiental com o objetivo de aproximar os alunos e professores à realidade da Caatinga pode resultar em uma maior sensibilização e reflexão, no que diz respeito à restauração e conservação desse ecossistema da região semiárida brasileira.

\section{Agradecimentos}

Ao Programa de Pós-graduação em Ciência e Tecnologia Ambiental (PPGCTA) da Universidade de Pernambuco Campus Petrolina.

À Coordenação de Aperfeiçoamento de Pessoal de Nível Superior (CAPES), Brasil - Código de Financiamento 001.

À Fundação de Amparo a Ciência e Tecnologia do Estado de Pernambuco (FACEPE) pela concessão de bolsas e financiamento do projeto "Aprendendo sobre o valor da biodiversidade da Caatinga e seus serviços ecossistêmicos no ensino escolar" (FACEPE APQ - 0177-2.05/18). 


\section{Referências}

ALVES, F. Gamification: como criar experiências de aprendizagem engajadoras: um guia completo do conceito à prática. São Paulo: DVS Editora, 2014.

ANTONGIOVANNI, M. et al. Chronic anthropogenic disturbance on Caatinga dry forest fragments. Journal of Applied Ecology, v. 57, n. 10, p. 2064-2074, 2020.

ARNAN, $X$. et al. Increased anthropogenic disturbance and aridity reduce phylogenetic and functional diversity of ant communities in Caatinga dry forest. Science of the Total Environment, v. 631-632, p. 429-438, 2018.

AVERY, P. M.; MICHALEWICZ, Z. Adapting to human gamers using coevolution. In: Advances machine learning II. Berlin: Springer, 2010. p. 75100. Disponível em: <http://link.springer.com/10.1007/978-3-642-05179-1 4>.

BRAZIL, A. L.; ALBAGLI, S. Os usos da gamificação na mobilização cognitiva da ciência cidadã online. Encontros bibli: revista eletrônica de biblioteconomia e ciência da informação, v. 25, p. 01-21, 2020.

BRISOLLA, L. A prática pedagógica no ensino superior: planejamento, interdisciplinaridade e metodologias ativas. Devir educação, v. 4, n. 1, p. 7792, 2020.

BUSATO, M. A.; AREZI, B. A.; SOUZA, M. A.; TEO, C. R. P. A.; LUTINSKI, J. A.; FERRAZ, L. Uso e manuseio de agrotóxicos na produção de alimentos da agricultura familiar e sua relação com a saúde e o meio ambiente. Holos, v. 1, p. 1-9, 2019.

CARSON, R. Primavera silenciosa. 2 ed. São Paulo: Melhoramentos, 1969.

CHOU, Y.K. Actionable gamification: beyond points, badges, and leaderboards. Packt publishing, 2016.

SOUZA, C. F. Aprendizagem sem distância: tecnologia digital móvel no ensino de língua inglesa. Texto Livre: Linguagem e Tecnologia, v. 8, n. 1, p. 39-50, 2015.

FERREIRA, R.; MOROSINI, M. Metodologias ativas: as evidências da formação continuada de docentes no ensino superior. Revista Docência do Ensino Superior, v. 9, e002543, 2019.

FREIRE, N. C. F.; PACHECO, A. P. Uma abordagem geoespacial e espectrotemporal da degradação ambiental no bioma Caatinga na região de Xingó, Brasil. Ciência \& Trópico, v. 41, n. 2, p. 97-128, 2017.

GIURGIU, L. Microlearning an evolving elearning trend. Scientific Bulletin, v. 22, n. 1, p. 18-23, 2017.

JOYE, C. R.; MOREIRA, M. M.; ROCHA, S. S. D. Educação a distância ou atividade educacional remota emergencial: em busca do elo perdido da educação escolar em tempos de Covid-19. Research, Society and Development, v. 9, n. 7, p. 1-29, 2020.

revista brasileira educação ambiental 
KINGSLEY, T. L.; GRABNER-HAGEN, M. M. Vocabulary by gamification. The Reading Teacher, v. 71, n. 5, p. 545-555, 2018.

LIMA-BOHNER, T. O.; ARAÚJO, L. E. B.; NISHIJIMA, T. O impacto ambiental do uso de agrotóxicos no meio ambiente e na saúde dos trabalhadores rurais. Revista eletrônica do curso de direito da UFSM, v. 8, p. 329, 2013.

MARTINS, A.; MAIA, M.; TINTI, D. S. Utilizando a gamificação em uma intervenção pedagógica nas aulas de matemática do $7^{\circ}$ ano. Revista Insignare Scientia - RIS, v. 3, n. 1, p. 309-321, 2020.

MARTINS, C.; GIRAFFA, L. M. M. Design de práticas pedagógicas incluindo elementos de jogos digitais em atividades gamificadas. Obra Digital, n. 10, p. 56-67, 2016.

MENEZES, C.; BORTOLI, R.; ALMEIDA, C. P. Mapeamento tecnológico de patentes relacionadas à gamificação. Encontros Bibli: Revista Eletrônica de Biblioteconomia e Ciência da Informação, v. 22, n. 49, p. 33, 2017.

PEREIRA, M. P. S. et al. Brazilian dry forest (Caatinga) response to multiple ENSO: the role of atlantic and pacific ocean. Science of the Total Environment, v. 705, p. 135717, 2020.

QUINTANILHA, L. F. Inovação pedagógica universitária mediada pelo facebook e youtube: uma experiência de ensino-aprendizagem direcionado à geração-Z. Educar em Revista, n. 65, p. 249-263, 2017.

RIBEIRO, V. G. et al. Emprego de técnicas de gamificação na educação científica: relato de uma intervenção como apoio à estatística. Research, Society and Development, v. 9, n. 1, p. 1-22, 2020.

SAMPAIO, R. M. Práticas de ensino e letramentos em tempos de pandemia da covid-19. Research, Society and Development, v. 9, n. 7, p. 1-16, 2020.

SANTOS, A.M.; SILVA JÚNIOR, M. F.; LOPES, E. R. N. Gamificando a Educação Ambiental: o desafio jogando verde no Instituto Federal Baiano. Revista Brasileira de Educação Ambiental (RevBEA), v. 11 n. 1, p. 245-263, 2016.

VICENTE, R. B.; ARAÚJO, M. Y. B. S. Aplicativo digital: uma contribuição para o processo de ensino-aprendizagem. Texto Livre: Linguagem e Tecnologia, v. 10, n. 2, p. 169-184, 2017.

WITTER, G. P. Ensino-aprendizagem virtual. Psicologia Escolar e Educacional, v. 15, n. 2, p. 351-352, 2011.

$\mathrm{XI}, \mathrm{N}$.; HAMARI, J. Does gamification affect brand engagement and equity? A study in online brand communities. Journal of Business Research, v. 109, p. 449-460, 2020. 